\title{
An Investigation of The Cooperative Learning Using Audio Visual Media in Speaking Skill Subject
}

\author{
${ }^{1}$ Agus Darmuki, ${ }^{2}$ Nur Alfin Hidayati \\ 1agus_darmuki@yahoo.co.id,_2nikidanajwasalsabila@gmail.com \\ ${ }^{1,2}$ IKIP PGRI Bojonegoro, Indonesia
}

\begin{abstract}
The objective of this present research is to understand how lecturers apply the cooperative learning technique in the class and how is the effective of this application technique using audio visual media in developing university students' speaking skill. This research was made in two classes and a qualitative approach adoption. The techniques employed in collecting the main data were classroom observations, interviews with groups of students and lecturers to obtain some insights of the application of the cooperative learning technique and students' oral expressions and behavior to the learning activities in small groups using audio visual media. From the research findings, it is shown that a cooperative learning using audio visual media in a small group could improve the students' speaking skill and ensure that the application of the cooperative learning technique had negative aspects such as noises and conflicts, when the lecturers did not manage and plan the learning activities maximally. Based on the research results, it is recommended that either lecturers and students are able to reduce any problems hindering the success of the application of the cooperative learning technique using audio visual in the class.
\end{abstract}

Keywords: Cooperative; Learning; Investigation; Speaking; Skill Subject

\section{Introduction}

The paradigm of language teaching has shifted from Teacher-Centered Learning, where the learning activities are centered on lecturers, to Student-Centered Learning, where activities in the class are centered on students who influence one another in terms of their knowledge and skill [1]. Based on the idea, cooperative learning technique has emerged to facilitate learning through interactions made by students when they work in pairs or in small groups, which have been defined by Coetzee, Niekerk \& Qydeman[2] as a team approach to learning where each member of the group depends on one and each other in completing tasks or certain tasks.

Unlike traditional teaching technique, Kagan[3] stated that lectures applying cooperative learning technique give their students chances to interact and vary their learning styles so that the students are interested in their learning tasks. Giving chances to interact and vary learning styles needed in developing one of language skills is speaking skill Hengki[4]. Speaking skill is one of the basis of language learning Thuy[5]. This skill plays an important role in language learning through times and involves various types of knowledge, either linguistic or non linguistic Bygate[6]. The objective of teaching the speaking skill is to develop student's oral ability so that they may effectively use their backgrounds to give responses coherently in a certain communicative situation Darmuki[7]. Speaking skill is one of the components of the basis of language teaching and learning besides reading, listening, reading and writing because it gives students chances to manage conversations successfully. 
Therefore, this research was intended to understand how the lecturers in the Institute of Teacher Training and Education PGRI (Teachers Association of the Republic of Indonesia) Bojonegoro apply the principles of cooperative learning in their classes to develop their students' speaking ability. They need to apply this approach which is more focused on students to create interactions among students and to develop their oral skill by making more comfortable and conducive classes so that the students feel free to speak without any feelings of shyness or reluctance, nervousness, and of no less-confidence.

On the basis of the background above, the objective of this present research is to (1) understand whether lecturers use the cooperative learning technique in their classes and how they apply the principles of cooperative learning in teaching speaking skill; (2) try to investigate problems the lectures encounter in teaching speaking skill in applying the cooperative learning technique in the teaching of speaking.

This kind of research is important since Cooperative approach to improving speaking skill has been rarely made, different from previous researches focused on the same topics. For instances, Kagan[3], Jhonson \& Johnson[8] focused their researches on improving the skill of reading comprehension using cooperative learning technique and its role in developing a language teaching so that in the future lecturers will be able to integrate its to teacher various aspects of language. Moreover, their researches also described the process of the classroom management of cooperative learning, and different challenges encountered by lecturers and groups in the classes when this technique was applied in different classes.

Therefore, this present research is intended to give some descriptions to lecturers and students about some proposed solutions beneficial for the use of cooperative learning using audio visual media in the future. One of the important issues related to the field of language teaching would be discussed. Audio Visual Media is a popular medium for use in teaching a foreign or second language. Many researchers have done research related to audio visual media. Educators have proved that the use of group works and use audio visual media has been praised as an effective way to develop students' oral language. Cooperative learning using audio visual media as a kind of the group work may serve as an icebreaker of students' silence since it may reduce their anxieties and low self-confidence and at the same time also facilitate communication in the class when it is effectively integrated by the lecturer.

\section{Literature Review}

Speaking is the personal product of creative construction of linguistic strings Brown[9], In other words, speaking is a productive skill where the speaker makes choices of lexicons, structures and discourses observed and interpreted by the listeners. Thorunbury[10] defines speaking as a natural integral part of one's daily life. In other words, it is an activity made by ordinary and specific persons to do their basic function which is in line with their specific needs. Trying to describe the process of speaking a language fluently, one claims that speaking is a complex skill that involves not only knowledge of vocabulary, grammar and pronunciation but also other types of knowledge Hengki[4] One expresses him/herself orally by observing, remembering, and articulating various voices and language constructions in a right order, and the three activities are called as motoreptive skill Bygate[6] The term "oral expression" includes making correct choices of language and orders to produce a native speaker like-language and proper meanings so that speakers need listeners to understand the condition showing how best we speak. Speaking under the framework of language teaching is when oral expressions not only involve a proper pattern of rhythm and intonation but also 
proper choices $\mathrm{f}$ words and inflections in correct orders to convey proper meanings. AlTamimi \& Attamimi[11].

Various efforts have been made to study the process of teaching speaking. Thorunbury[10] emphasized that speaking is a complex skill where a speaker should do certain things and develop a command of skills such as pronunciation production, conceptualization, formulation, articulation and management interaction. In the application of learning speaking in the field, speaking is not only at a theoretical but also psychological level, one of which a bravery to speak[7]. A bravery to speak is a psychological factor related to one' s self confidence to dare to appear in public. In this case, cooperative learning is one of learning methods that may promote one's motivation and self-confidence, since students will be trained to speak in small groups with some inputs and they would learn to improve their speaking skill with their classmates in a pleasing environment.

In recent years, great efforts have been made by educators to make learning more centered on students and increase the number of interactions in the class by adopting a cooperative learning approach. This approach has been being developed based on various psychological theories and is rooted from social, development and humanism theories. Frank[12] defines learning theory as "a systematic study on how exchanges with others in our environment would influence our thoughts, feelings and actions. Moreover, Frank has an idea that human beings are social beings of whom their attitudes happen in group settings such as families, schools, and the like that may automatically imply interactions with other people. On the basis of the idea, a good cooperative class environment is expected to be able to apply principles of social psychology successfully.

Besides influences of social psychology to the establishment of learning groups, the development of cooperative learning approach has also been influenced by Piaget and Vigotsky's developmental psychology Vygotsky[13]. According to McCafferty et all (2006), cooperative learning approach has been developed in line with Piaget's idea on how an individual builds their own knowledge about the environment around them to establish their background knowledge. Piaget's idea has been by many educators such as Doise and Mugny (1995) and Murry (1982) stating that the values of social context have increased productive cognitive conflicts that may be applied in a class environment to result in students to be involved in their own learning, to play active roles and to be involved in doing realistic tasks and to make them find how to work together among two students with low academic achievement may help them finish their tasks, where the tasks would not well finish when they work individually. Unlike Piaget, Vigotsky support the roles of an individual's sociocultural knowledge in building his/her knowledge about the world. He has developed of what is called a socio-cultural development theory.

Among ideas conveyed by educators in the development of cooperative learning approach is humanist psychology, as proposed by Maslow and Rogers. Maslow (1968) proposes a hierarchy of needs: maintenance and growth. The fulfillment of this need is required for survival and growth. This then includes the needs for knowing and understanding, aesthetics, realizing one's potential and need for making relation with something out of oneself. Rogers (1979) also shows that students should develop interpersonal relationships for their psychological growth. Although cooperative learning is based on interpersonal interactions and ideas proposed by Maslow and Rogers, it is also on the basis of individual development. This idea is considered in developing a cooperative learning approach since students learn cooperatively in their effort to reach the learning goal. Therefore, learning is dependent upon an individual and his/her fellow[14]. Cooperative learning has proved to be a technique that support and motivate students to behave positively in terms of language 
learning and of the way to reduce negative behaviors Alabekee \& Samuel[15]. The first key to the success in the application of cooperative learning is a well-managed cooperative class. An effective cooperative class management is often dependent upon successful group works and works in pair, clear rules, well-formed groups, optimal group size and cohesive group.

Ivers and Baron[16] defines multimedia allows the understanding of a topic to be conveyed in a variety of ways with provides students with opportunities to explain their ideas to others and provides students with a medium for communication or offers them new insights into organizing and evaluating information. Besides, multimedia has the potential to change the roles of teachers and students and the interactions between them by allowing students to create their own interpretations of information. Mayer[17] state that multimedia as the combination of various digital media types, such as text, image, sound, and video, into an integrated multi-sensory interactive application or presentation to convey a message or information to an audience and potential benefits of multimedia that humans possess visual and auditory information processing capabilities.

Reddy[18] describes "audio visual education consists of the uses of interactional devices such as film projectors, radio, television, charts, posters, models, field trips etc." According to Madhuri[19], AVM tools for students can improve speaking skills several times over, more than other methods. AVM can be defined as stimulating materials and devices which aid sound and sight in teaching to facilitate learning by students by activating more than one sensory channel.

\section{Material \& Methodology}

A qualitative approach was employed in this present research. Two classes with 41 students each in the study program of Indonesian Language and Arts were observed. The techniques of data collected used were class observations, group interviews and interviews with lecturers intended to help the researcher get insights of how the lecturers applied the cooperative learning, of the students' oral expressions and attitudes towards learning in small groups. The number of lecturers interviewed was 6 persons in the study program of Indonesian Language and Arts in Institute of Teacher Training and Education "PGRI" Bojonegoro. Their teaching experiences were from 2 to 17 years. The lecturers interviewed were those who were and once taught a speaking skill using a cooperative approach. Observation in the class were mad in 3 sessions in each class to obtain accurate data, while interviews with lecturers consisted of 10 questions.

\section{Results and Discussion}

\subsection{Result of Observation}

On the basis of the results of the observations, it is shown that most physical settings where the cooperative learning was implemented sometimes are appropriate for cooperative learning. In all sessions where a cooperative learning technique was implemented by teachers, groups were always randomly established by students. In other words, in one group, one might find members with mixed abilities and gender. Moreover, one might found a group where the members had the same ages, sex and abilities. Moving chairs to make the distance among students to create a group did not take long time. Most sessions were proceeded in an organized and wide room, but problems happened when students should move tables and chairs to sit closely one another and to form a cycle surrounded tables, and also when students should determine who would present their ideas before the class. The management of the activities took 5 to 10 minutes, depending on the numbers of the students. But the tables and chairs in the first classroom where the researcher attended two sessions fully were not well 
managed; the tables were placed in too nearly one another, half of the tables and chairs were not needed. The feature of this space hindered teachers to move around the group to monitor the students' work and it required the students to move the tables and the chairs, and this resulted in noisy and time consuming.

Moreover, from our observations, the teachers did not have any touch in grouping the students since they thought that it could give students chances to choose with whom they work with the hope that students may create a harmony in a group, reduce shyness among students, improve their motivation to collaborate and and reduce conflict in a group. But Kagan (2009) proved that a team containing students with high, moderate and low abilities, and with various gender, language and race would be better in order to develop peer guidance and to facilitate the acquisition and recognition of new information and also to improve students' social and racial relationship. According to the observations, in the cooperative learning in the three sessions in the first class, some members of the class had changed. This might be that the cooperative learning was conducted in late hours so that some students went home and were substituted by other students. Moreover, the observations of the two classes also showed that during the cooperative learning, the lecturers established groups consisting of four to five students each. The lecturers always limited the number of students in each group.

The effectiveness of groups consisting of four to five students has been proved by some researchers such Gillis[20]; Hosain \& Tarmizi[21]; Adebayo \& Judith[22]; Sühendan \& Bengü[23]; Han[24]; Hengki[4]; Darmuki[7]; Darmuki[25] stating the an optimal size for a successful cooperative group seems to consist of three to four students, since in this small group, students may be more involved in tasks and have more chances to speak and discuss and they may be observed by the teacher easily. In terms of the participation, the participation among students were not relatively the same where those showing more participations were usually the head of groups and students with high language ability. The results show that all students in all groups developed high individual and group accountability, where this is one of the features of the cooperative learning, and it is this feature that distinguish between a cooperative learning and a group work. In other words, all students showed their responsibility to complete their job on time and their success in expressing their thoughts.

Moreover, from the researchers' observations, the students felt relaxed and motivated to work and participate to attain their common goal and this reflects their positive attitudes to work in small groups. Moreover, in one session, the lecturer asked the students to give some suggestions on what to do since the students were not really ready to play their roles and some of the students were not present. Some students suggested a group game and all members agreed with the idea and it turned out that some positive attitude toward the work in small groups.

Students also showed their willingness to work with their peers since they felt that their classmates were present to give them some help and motivation needed and to correct their work before presentation. Then, during the group oral presentations, some students worked in a harmonious and relaxed way and each felt comfortable as expected. But some groups worked better than the others and even some individuals in the same group spoke more fluently than their fellow students in their groups. But it might deals with individual differences.

The results of observations also showed that almost all groups in the sessions observed sometimes consisted of some students who did not contribute to the task for example by giving solutions or ideas. The silent students might be shy, not interesting in the topics, or there might be some of his best classmates who did not join in the groups. But, few groups were well managed where all members of the groups spoke in turn in a good order. The 
problem where certain members of the groups did not take part in the work may be reduced if the lecturers monitor the groups so that they would feel to be paid attention or other students encourage shy students to speak, and as a result they would try harder to participate in the activity.

The observations above showed that the lecturers sometimes evaluated students' work and progress by observing them directly or indirectly. Moreover, members of the groups, after presentation, were evaluated by the lectures in either individually or in groups and were given feedbacks important for them since the feedbacks contained some encouraging motivations or some criticisms that may be used by students to do something better in the future. Although classroom observations gave opportunities to the researchers to observe their work and data of their real work, the researchers' observation was focused on the groups and the lecturers with good performance because it is difficult to observe all groups and the lecturers at the same time, especially since the number of sessions the researchers attended to was not enough to be generalized. As a consequence, the researchers had made two interviews namely those with lecturers and groups.

\subsection{Result of Interview}

On the basis of the results of the observations, it is shown that most physical settings where the cooperative learning was implemented sometimes are appropriate for cooperative learning. In all sessions where a cooperative learning technique was implemented by teachers, groups were always randomly established by students. In other words, in one group, one might find members with mixed abilities and gender. Moreover, one might found a group where the members had the same ages, sex and abilities. Moving chairs to make the distance among students to create a group did not take long time. Most sessions were proceeded in an organized and wide room, but problems happened when students should move tables and chairs to sit closely one another and to form a cycle surrounded tables, and also when students should determine who would present their ideas before the class. The management of the activities took 5 to 10 minutes, depending on the numbers of the students. But the tables and chairs in the first classroom where the researcher attended two sessions fully were not well managed; the tables were placed in too nearly one another, half of the tables and chairs were not needed. The feature of this space hindered teachers to move around the group to monitor the students' work and it required the students to move the tables and the chairs, and this resulted in noisy and time consuming.

Moreover, from our observations, the teachers did not have any touch in grouping the students since they thought that it could give students chances to choose with whom they work with the hope that students may create a harmony in a group, reduce shyness among students, improve their motivation to collaborate and and reduce conflict in a group. But Kagan[3] proved that a team containing students with high, moderate and low abilities, and with various gender, language and race would be better in order to develop peer guidance and to facilitate the acquisition and recognition of new information and also to improve students' social and racial relationship. According to the observations, in the cooperative learning in the three sessions in the first class, some members of the class had changed. This might be that the cooperative learning was conducted in late hours so that some students went home and were substituted by other students. Moreover, the observations of the two classes also showed that during the cooperative learning, the lecturers established groups consisting of four to five students each. The lecturers always limited the number of students in each group.

The effectiveness of groups consisting of four to five students has been proved by some researchers such Gillis[20]; Hosain \& Tarmizi[21]; Adebayo \& Judith[22]; Sühendan \& 
Bengü[23]; Han[24]; Hengki[4]; Darmuki[7] stating the an optimal size for a successful cooperative group seems to consist of three to four students, since in this small group, students may be more involved in tasks and have more chances to speak and discuss and they may be observed by the teacher easily. In terms of the participation, the participation among students were not relatively the same where those showing more participations were usually the head of groups and students with high language ability. The results show that all students in all groups developed high individual and group accountability, where this is one of the features of the cooperative learning, and it is this feature that distinguish between a cooperative learning and a group work. In other words, all students showed their responsibility to complete their job on time and their success in expressing their thoughts.

Moreover, from the researchers' observations, the students felt relaxed and motivated to work and participate to attain their common goal and this reflects their positive attitudes to work in small groups. Moreover, in one session, the lecturer asked the students to give some suggestions on what to do since the students were not really ready to play their roles and some of the students were not present. Some students suggested a group game and all members agreed with the idea and it turned out that some positive attitude toward the work in small groups.

Students also showed their willingness to work with their peers since they felt that their classmates were present to give them some help and motivation needed and to correct their work before presentation. Then, during the group oral presentations, some students worked in a harmonious and relaxed way and each felt comfortable as expected. But some groups worked better than the others and even some individuals in the same group spoke more fluently than their fellow students in their groups. But it might deals with individual differences.

The results of observations also showed that almost all groups in the sessions observed sometimes consisted of some students who did not contribute to the task for example by giving solutions or ideas. The silent students might be shy, not interesting in the topics, or there might be some of his best classmates who did not join in the groups. But, few groups were well managed where all members of the groups spoke in turn in a good order. The problem where certain members of the groups did not take part in the work may be reduced if the lecturers monitor the groups so that they would feel to be paid attention or other students encourage shy students to speak, and as a result they would try harder to participate in the activity.

The observations above showed that the lecturers sometimes evaluated students' work and progress by observing them directly or indirectly. Moreover, members of the groups, after presentation, were evaluated by the lectures in either individually or in groups and were given feedbacks important for them since the feedbacks contained some encouraging motivations or some criticisms that may be used by students to do something better in the future. Although classroom observations gave opportunities to the researchers to observe their work and data of their real work, the researchers' observation was focused on the groups and the lecturers with good performance because it is difficult to observe all groups and the lecturers at the same time, especially since the number of sessions the researchers attended to was not enough to be generalized. As a consequence, the researchers had made two interviews namely those with lecturers and groups. 


\section{Conclusion}

From the data obtained from class observations, group interviews and lectures it is shown lecturers adopted a cooperative learning and integrated it with speaking skills using audio visual media. The findings also confirmed that "sizes and heterogeneity in groups students, time management and lecturers" are positive factors of the success in applying the cooperative learning using audio visual media. This research finding also firmly stated that students' speaking skills were developed by immersing students a small-structured group and using audio visual media, it turned out their interactions number increased.

This research also marks that the application of cooperative learning using audio visual media consisted of certain negative aspect such as creating noisy in the class, conflicts among groups and students who did not want to join in some groups. This negative aspect may hinder the success of the cooperative learning application.

Acknowledgement. This research is fully supported by IKIP PGRI Bojonegoro.

\section{References}

[1] J. Crandall, Cooperative language learning and affective factors. Cambridge: Cambridge University Press, 1999.

[2] J. . Coetzee, S.A., Niekerk, E.J.V., Wydeman, An educators' guide to effective classroom management. Hatfield: Van Scadaik Publishers, 2008.

[3] S. K. Kagan, cooperative learning. San Clemente: Kagan Publishing, 2009.

[4] K. Hengki, H.; Jabu, B. Salija, "The effectiveness of cooperative learning strategy through english village for teaching speaking skill," J. Lang. Teach. Res., vol. 8, no. 2, pp. 306-312, 2017.

[5] L. T. B. Thuy, "An action research on the application of cooperative learning to teaching speaking," TESOL. J., vol. 3, no. 2, pp. 131-140, 2015.

[6] M. Bygate, Speaking. Oxford: Oxford University Press, 2000.

[7] K. S. Darmuki, A., Andayani, Joko Nurkamto, "Evaluating Information-ProcessingBased Learning Cooperative Model on Speaking Skill Course," J. Lang. Teach. Reasearch, vol. 8, no. 1, pp. 44-51, 2017.

[8] R. . Jhonson, D. W., Jhonson, Social interdependence theory and cooperative learning: The teachers. New York: Springer, 2008.

[9] D. Brown, Language assessment principles and classroom practices. Pearson: Longman, 2004.

[10] S. Thorunbury, How to teach speaking. Longman, 2005.

[11] R. A. A. N. . Al-Tamimi, "Effectiveness of Cooperative Learning in Enhancing Speaking Skills and Attitudes towards Learning English," Int. J. Linguist., vol. 6, no. 4, pp. 27-45, 2014.

[12] J. B. Frank, Psychology: a self teaching guide. Hoboken, 2002.

[13] L. M. Schreiber and B. E. Valle, "Social Constructivist Teaching Strategies in the Small Group Classroom," Small Gr. Res., vol. 44, no. 4, pp. 395-411, Aug. 2013.

[14] J. MacCarten, Teaching vocabulary: Lessons from the corpus, lessons for the classroom. Cambridge: Cambridge University Press, 2007.

[15] A. Alabekee, E. C. Samuel, "Effect of cooperative learning strategy on students learning experience and achievements in mathematics," Int. J. Educ. Learn. Dev., vol. 3, no. 4, pp. $67-75,2015$. 
[16] A. Ivers, K., Baron, Multimedia Project in Education. Santa Barbara: ABC- CLIO LLC, 2002.

[17] R. E. Mayer, Multimedia Learning. Cambridge: Cambridge University Press, 2001.

[18] R. J. Reddy, Methods of Teaching. New Delhi: S.B Nangia, 2008.

[19] J. N. Madhuri, "Use of Audio Visual Aids in Teaching and Speaking," Res. J. English Lang. Lit., vol. 1, no. 3, pp. 108-122, 2013.

[20] \& P. C. A. McWhow, K., Shanckenberg, H. S., From Cooperation to Collaboration: helping students to become collaborative learners. In R. M. Gillis, A, 2003.

[21] R. A. Hossain, A., Tarmizi, "Effects of cooperative learning on students' achievement and attitudes in secondary mathematics," Procedia-Social Behav. Sci., vol. 93, no. 3, pp. 473-477, 2013.

[22] K. Adebayo, A. S. Judith, “. Comparative study of effectiveness of cooperative learning strategy and traditional instructional method in physics classroom: A case study of Chibote girls secondary school, Kitwe district, Zambia," Eur. J. Educ. Sci., vol. 1, no. 1, pp. 30-41, 2014.

[23] A. A. Sühendan, E. R., Bengü, "The attitudes of students towards cooperative learning in ELT classes," Int. Online J. Educ. Teach., vol. 1, no. 2, pp. 31-45, 2014.

[24] M. Han, "An empirical study on the application of cooperative learning to english listening classes," English Lang. Teach., vol. 8, no. 3, pp. 177-184, 1998.

[25] K. S. Darmuki, A., Andayani, Joko Nurkamto, "The Development and Evaluation of Speaking Learning Model by Cooperative Approach,” Int. J. Instr., vol. 11, no. 2, pp. 115-128, 2018. 